\title{
Redox-induced Reversible Conformational Switching of Poly(Aniline Sulfonic Acid) with Transition Metals in Aqueous Solution
}

\author{
Toru Amaya, Daisuke Saio, Shogo Koga, and Toshikazu Hirao* \\ Department of Applied Chemistry, Graduate School of Engineering, Osaka University \\ Yamada-oka, Suita, Osaka 565-0871, Japan
}

\section{Supporting information}

\section{General procedure for the experiments of the conformational change}

Poly(2-methoxyaniline-5-sulfonic acid) (PMAS), which was kindly provided by Mitsubishi Rayon Co., was deionised through cation-exchange resins before use. Other reagents were used as received. To a disposable UV cell with a stirrer chip, were added Milli-Q water (2640 $\mu \mathrm{L}), 10 \mathrm{mM} \mathrm{B}(\mathrm{OH})_{3}-\mathrm{NaOH}$ buffer solution $(300 \mu \mathrm{L})$, and $10 \mathrm{mM}$ aqueous PMAS solution $(30 \mu \mathrm{L})$. Then, an aqueous solution of metal salt $(30 \mu \mathrm{L})$ was added at $25{ }^{\circ} \mathrm{C}$ under air. The mixture was stirred at $25^{\circ} \mathrm{C}$. The conformational change was monitored by UV-vis-NIR spectroscopy (HITACHI U-3500).

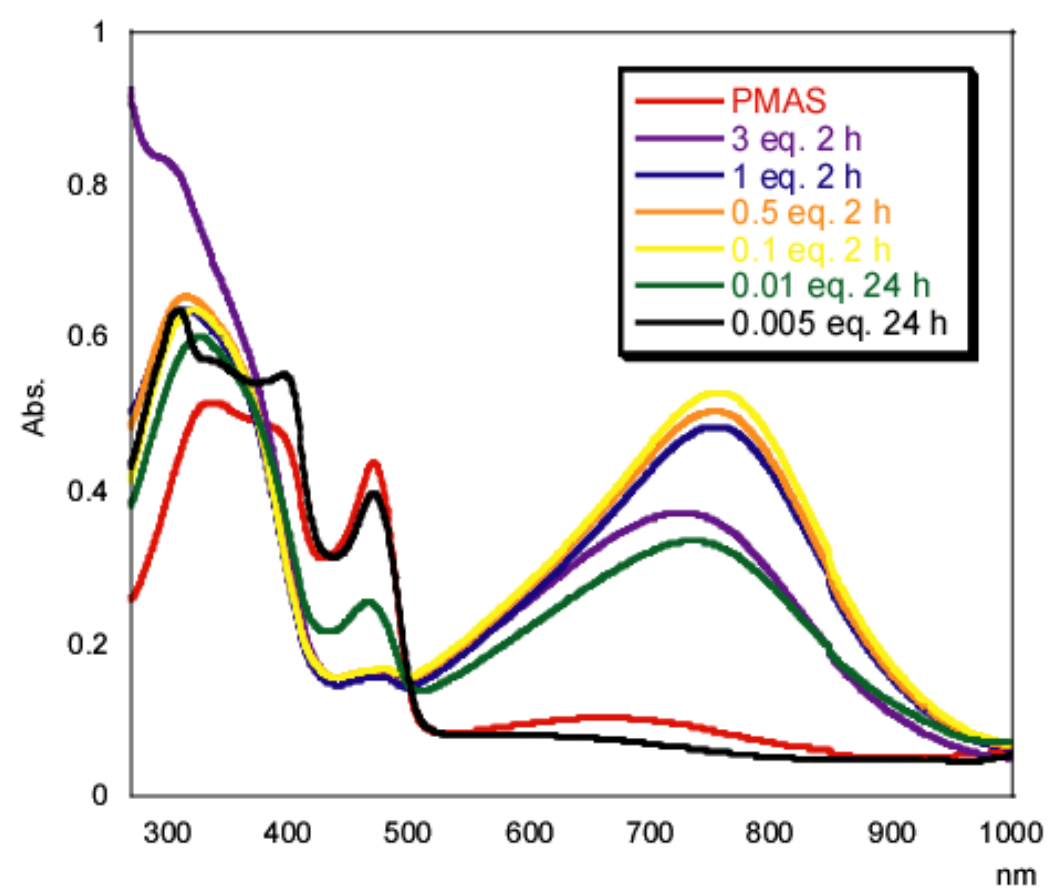

Figure S1. UV-vis-NIR spectra of (ES)PMAS in $\mathrm{pH} 8.8$ buffer solution with various amounts of $\mathrm{Cu}(\mathrm{OAc})_{2}$ under air at $25^{\circ} \mathrm{C}$ (PMAS: $1.0 \times 10^{-4} \mathrm{M}$ based on the aniline monomer unit, the spectra after $2 \mathrm{~h}: 3,1,0.5$, and 0.1 eq. of $\mathrm{Cu}(\mathrm{OAc})_{2}$, the spectra after $24 \mathrm{~h}: 0.01$ and 0.005 eq. of $\left.\mathrm{Cu}(\mathrm{OAc})_{2}\right)$. 


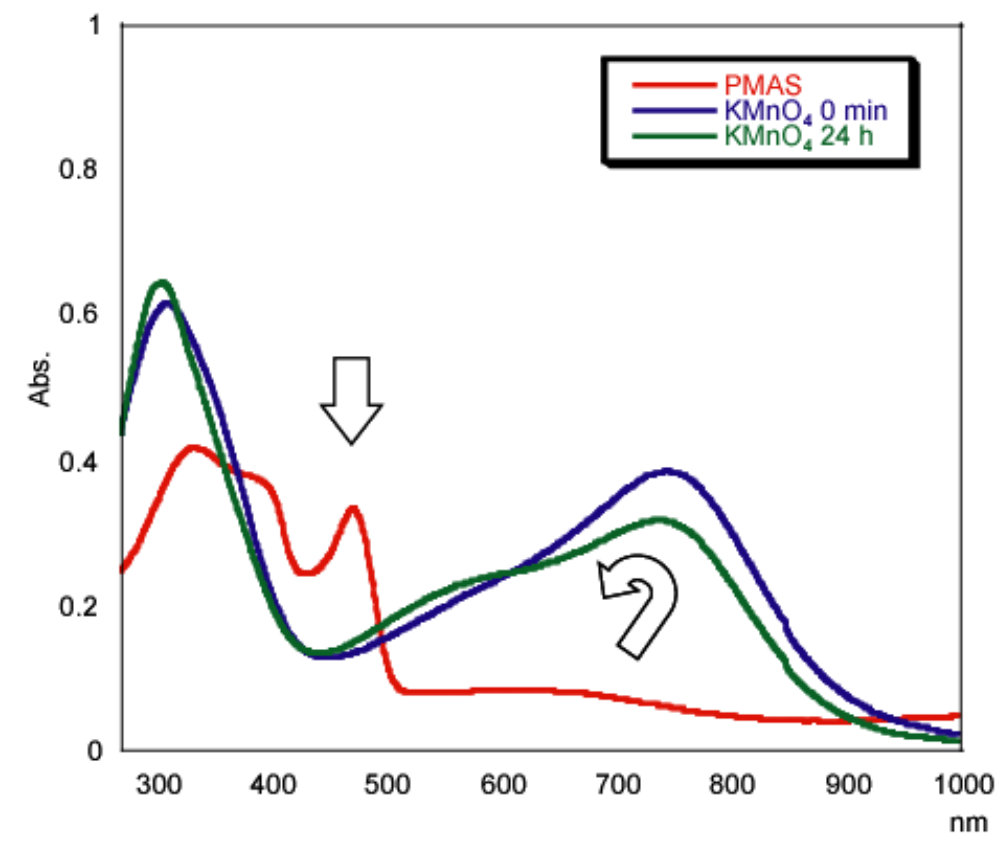

Figure S2. Time-dependent UV-vis-NIR spectra of (ES)PMAS in $\mathrm{pH} 8.8$ buffer solution with 0.1 eq. of $\mathrm{KMnO}_{4}$ under air at $25^{\circ} \mathrm{C}$ (PMAS: $1.0 \times 10^{-4} \mathrm{M}$ based on the aniline monomer unit, 0 min and 24 h).

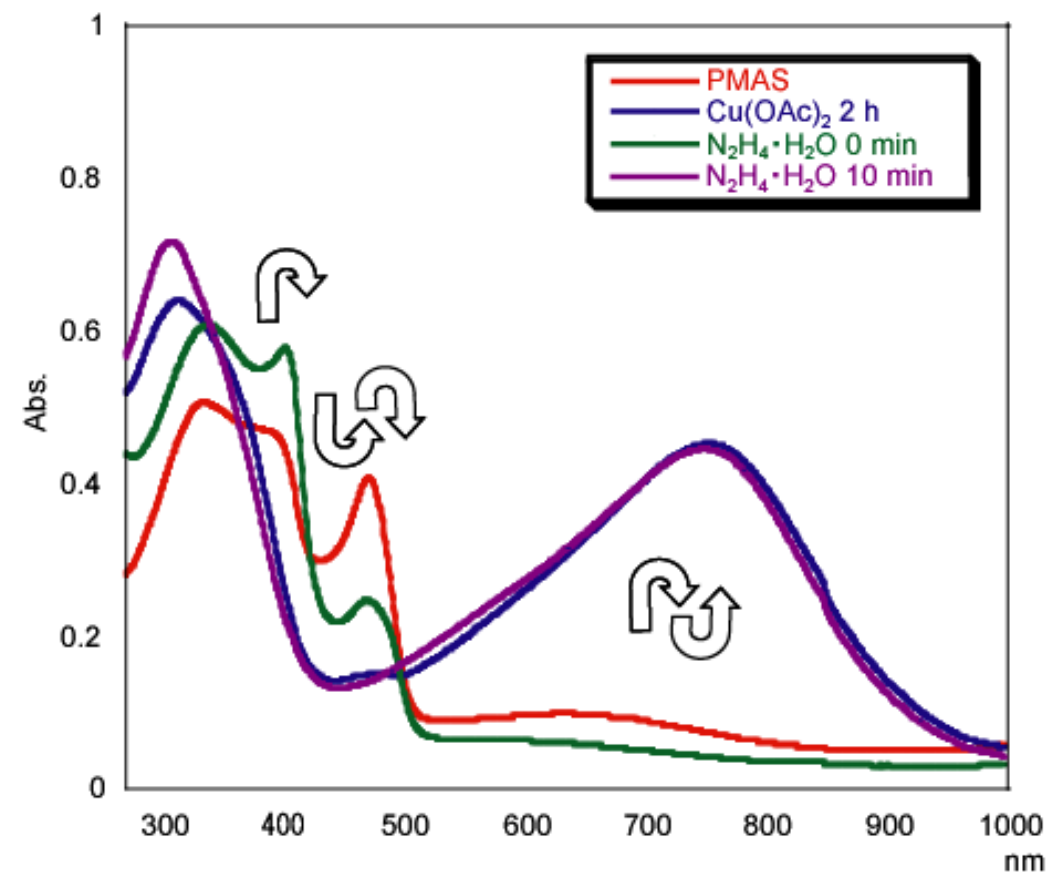

Figure S3. Time-dependent UV-vis-NIR spectra of (ES)PMAS compact coil in pH 8.8 buffer solution (prepared by treatment with 1 eq. of $\mathrm{Cu}(\mathrm{OAc})_{2}$ for $2 \mathrm{~h}$, blue line) with 1 eq. of $\mathrm{N}_{2} \mathrm{H}_{4} \cdot \mathrm{H}_{2} \mathrm{O}$ under air at $25^{\circ} \mathrm{C}$ (PMAS: $1.0 \times 10^{-4} \mathrm{M}$ based on the aniline monomer unit, 0 and $10 \mathrm{~min}$ ). 


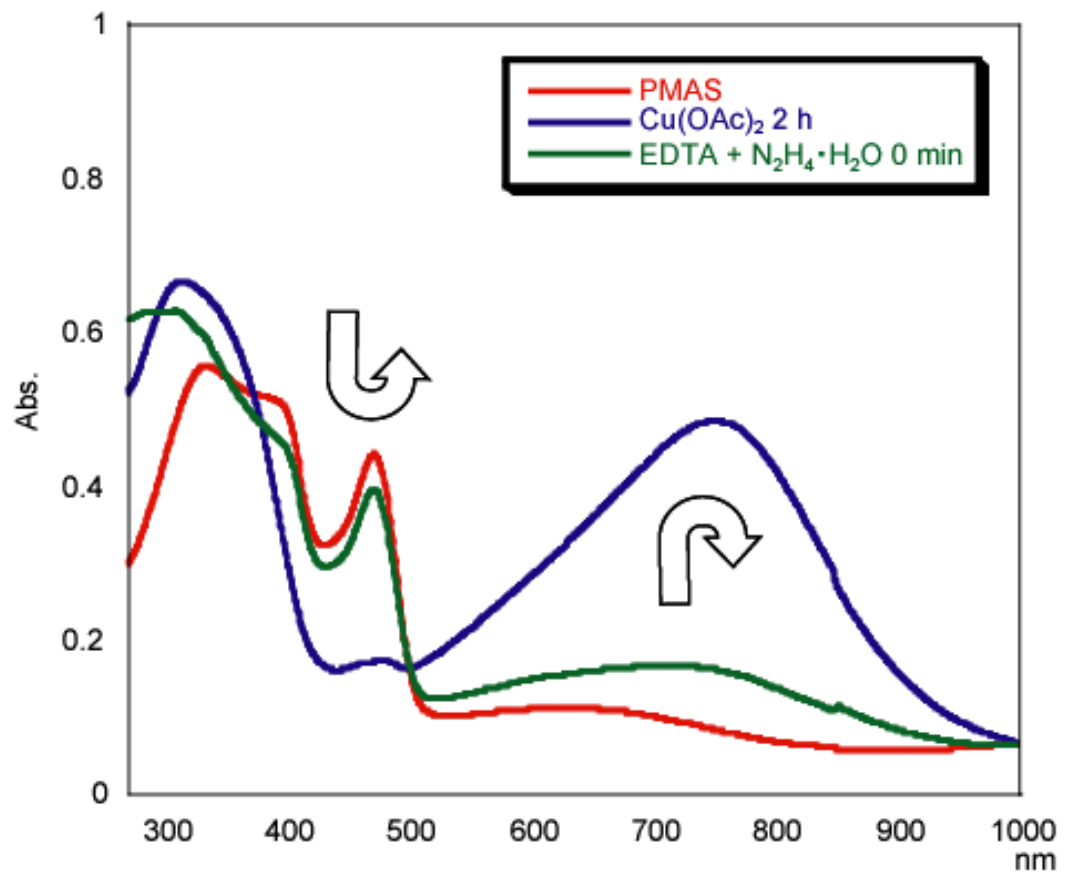

Figure S4. UV-vis-NIR spectra of (ES)PMAS compact coil in $\mathrm{pH} 8.8$ buffer solution (prepared by treatment with 1 eq. of $\mathrm{Cu}(\mathrm{OAc})_{2}$ for $2 \mathrm{~h}$, blue line) with 1 eq. of both EDTA and $\mathrm{N}_{2} \mathrm{H}_{4} \cdot \mathrm{H}_{2} \mathrm{O}$ under air at $25^{\circ} \mathrm{C}$ (PMAS: $1.0 \times 10^{-4} \mathrm{M}$ based on the aniline monomer unit, $0 \mathrm{~min}$ ). 